\title{
A ausência da branquitude exila a negritude
}

The absence of whiteness exiles blackness

\section{Bernadeth Alves}

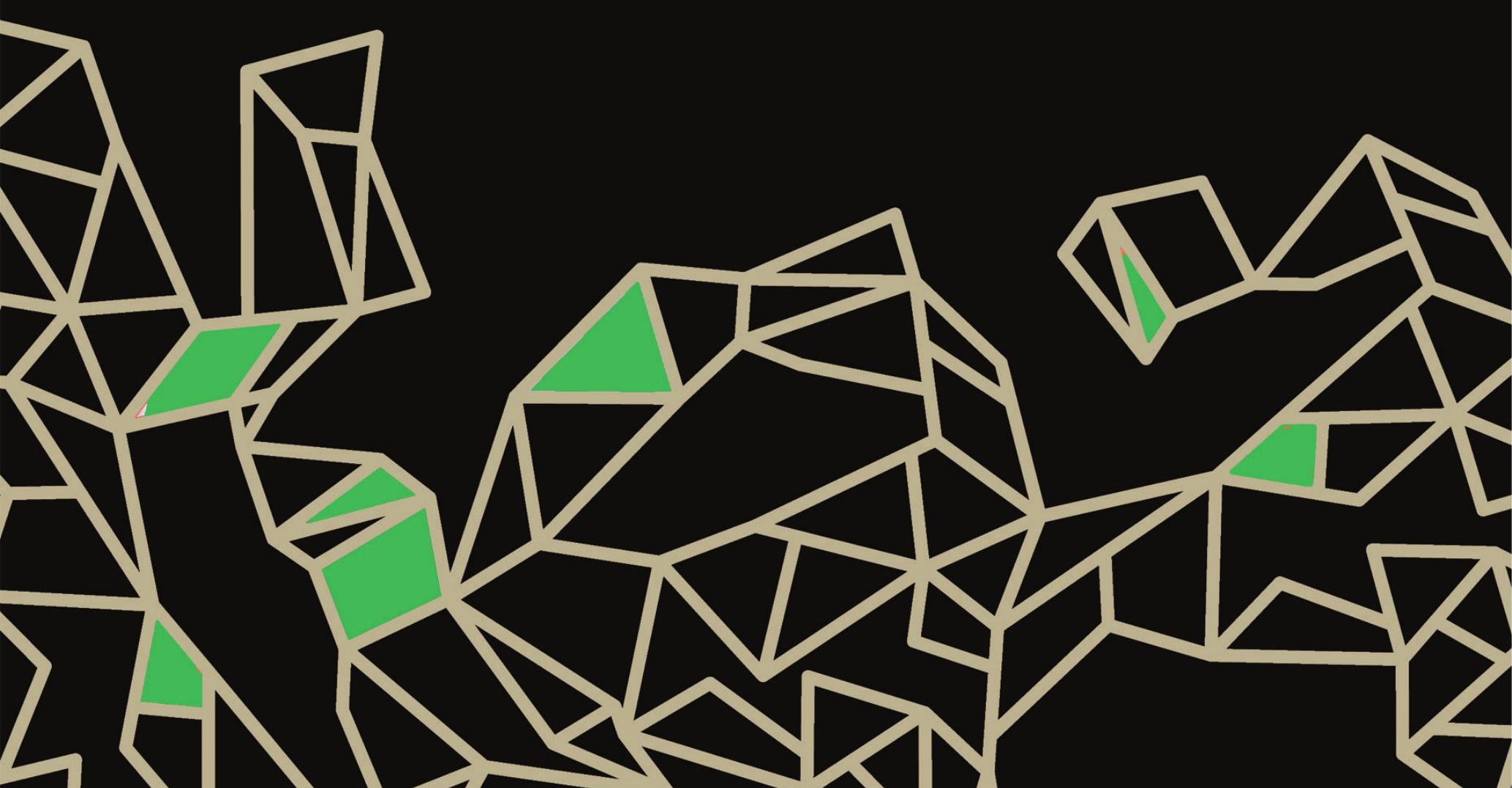




\section{Resumo}

$\mathrm{O}$ artigo procura refletir sobre a invisibilidade do negro na sociedade hegemônica branca, a partir da materialidade textual e cênica do espetáculo Branco: o cheiro do lírio e do formol.

Palavras-chave: Teatro, Teatro Negro, Identidade, Negritude.

\section{Abstract}

This article aims to reflect on the invisibility of black people in a white hegemonic society, from the textual and scenic materiality in Branco: 0 cheiro do lírio e do formol.

Keywords: Theater, Back theater, Identity, Blackness.

Por muito tempo achei que a ausência é falta.

E lastimava, ignorante, a falta.

Hoje não a lastimo.

Não há falta na ausência.

A ausência é um estar em mim.

E sinto-a, branca, tão pegada, aconchegada nos meus braços, que rio e danço e invento exclamações alegres, porque a ausência, essa ausência assimilada, ninguém a rouba mais de mim. Carlos Drummond de Andrade

Quase tudo ou pelo menos muito se falou sobre Branco: cheiro do lírio e do formol. As considerações traçadas se referiam a um espetáculo racista, que talvez não devesse ter estreado na Mostra Internacional de Teatro (MITsp). As calorosas discussões geradas pelo público presente nas três sessões instigaram ou desestimularam muitos a assistir ao espetáculo.

As inquietações dos discordantes giravam em torno da ousadia do dramaturgo Alexandre Dal Farra em abrir um lugar de fala ao branco, proposta que ecoou de antemão negativa, uma vez que o conceito de "lugar de fala" está atrelado à voz das minorias políticas não ouvidas pela sociedade hegemônica. Porém, o fato de um espetáculo ser gerador de tanta polêmica com um número irrisório de apresentações mereceria, no mínimo, reverência e análise. 
Algo muito confrontador deveria haver na montagem e desconsiderá-la seria um caminho fácil para não se sentir subjugado. Na reestreia, fomos assistir à peça. O espetáculo se mostrou muito mais complexo do que havíamos imaginado. Não era sobre a temática negra. Não havia negros. Praticamente não se falava de negros. Não era uma peça que discutia o problema do racismo. Não era uma peça deliberadamente racista. Era um relato verídico sobre as diversas tentativas de um artista branco escrever sobre o racismo.

Em uma sociedade, em que na última década o termo "negritude" se solidificou como afirmação da identidade cultural e em que negros clamam por igualdade étnica, pelo desmantelamento dos privilégios destinadas aos brancos e pela construção de uma identidade negra positiva, a proposta de abordar o assunto pelo viés do branco poderia ser uma possibilidade para a ampliação e para o aprofundamento do tema. Se a escravização está diretamente associada às condutas e atitudes do opressor, a responsabilidade do equilíbrio social não pode ser atribuída somente à minoria oprimida. A discussão não pode ser unilateral. A mudança de paradigma inclui a renovação da visão de mundo do branco sobre a população desvalida e desprestigiada.

O incessante e incansável trabalho dos movimentos e das comunidades negras militantes na reivindicação legítima de seus direitos e da reparação humanitária, em virtude das mazelas produzidas pela infinita dominação branca, deve-se à necessidade da sociedade hegemônica branca assumir que a inferioridade social do povo negro tem origem nas condutas desumanas de seus antepassados.

A construção da identidade social igualitária frutifica a partir da interação entre os indivíduos pertencentes à mesma sociedade. O sociólogo Lourenço Cardoso (2010, p. 51) aponta o conceito de branquitude como diretamente ligado à identidade construída pelo branco no decorrer da história, elevando-o ao topo da cadeia social. Entretanto, o pesquisador defende definições distintas para a questão: a branquidade crítica que desaprova publicamente o racismo e a branquitude acrítica, que não desaprova o racismo, mas aceita a raça branca como hierarquicamente superior, eximindo-se da autorresponsabilidade sobre as equiparações raciais.

Neste sentido, Alexandre Dal Farra, ao propor o projeto Branco: o cheiro do lírio e do formol, não pretendeu amenizar ou se esquivar do grave problema 
que assola nosso país há séculos. Pelo contrário, ao ambicionar mergulhar em si próprio para investigar o racismo em sua própria estirpe, sinaliza inquietações com o modus operandi e deseja construir novos padrões sociais.

Achei que não bastava ficar quieto. O movimento de afirmação do seu lugar de fala, por parte do negro, não podia ser usado pelos brancos como justificativa para ficarmos confortavelmente quietos, usufruindo do racismo que estrutura e dá condições de existência para esse nosso próprio silêncio. Nós também precisávamos tentar olhar para isso. $\mathrm{E}$ escutar, no caso, também era algo de ativo. Algo que o branco precisava construir. Construir um tipo de lugar de escuta. (DAL FARRA, 2017, p. 4)

O trecho reafirma a intenção explícita do dramaturgo em problematizar o comportamento do soberano e sugere a expansão da visão do opressor como ferramenta para a compreensão do oprimido. A proposta de autoanálise branca deseja jogar luz ao opressor, não para enaltecê-lo como agente positivo do sistema, mas visando reconhecer-se como colaborador e beneficiário do problema racial e social brasileiro.

Portanto, poetizar o racismo institucionalizado na raça branca surgiu como disparador para a investigação textual e cênica de Dal Farra e sua equipe. A dramaturgia provocativa factual e não fabular constitui-se de dezessete fragmentos monologados e dialógicos, escritos a partir das características contemporâneas. Por meio de alternância entre representações e relatos; indicações para os intérpretes; tempo cênico determinado por pausas e cortes bruscos; e a fusão de ficção e realidade, encontram-se subdivididas em três camadas narrativas distintas: os relatos do processo de escrita da peça, os trechos de ensaios da montagem e a família de classe média.

Os relatos elucidam ao público os caminhos tortuosos e conflitantes que fizeram com que a investigação, iniciada com o intuito de criticar o comportamento do homem branco perante o racismo, se modificasse e finalizasse com a mudança de olhar sobre o tema. As narrações dos fatos reais utilizam-se do gênero do teatro documental e hibridizam drama e comédia, concedendo ao texto final um status de tragédia autobiográfica do autor.

Lançando mão de expedientes do teatro épico, nas primeiras frases o dramaturgo narra humildemente não ter sido capaz de criar uma obra que criticasse o silêncio da classe dominante. Nos demais relatos, evidencia que 
a fricção entre o lugar de fala do branco e as provocações dos artistas negros que acompanharam o processo resultou no autoconhecimento do autor sobre o tema pesquisado:

E eu estava ali recebendo as acusações de racismo que eu nunca achei que fossem recair sobre mim. [...] Porque eu não me considerava racista! Nessa hora eu percebi. Eu realmente achava que eu não era racista; [...] não mais racista do que todos os brancos que preferem não tocar no assunto do racismo, eu não era mais racista do que isso, e eu era tão racista quanto qualquer um de nós, brancos. (Ibid., p. 20)

Em outra passagem documental, mais uma vez Dal Farra reconhece sua inoperância em atingir os objetivos iniciais ao falar sobre racismo, quando se observa a leitura do texto, as informações soavam:

Como se as falas não coubessem nas bocas de quem as proferiam. Eram palavras sem corpo, flutuando em um tipo de constelação conceitual do mundo - exata, precisa, certa, e também totalmente inútil. Achei que eu precisava aceitar: eu ia ter que escrever ainda um outro texto, inteiramente novo. (Ibid., p. 28)

A derradeira versão foi elaborada resgatando cenas da primeira e da segunda escritura. Entretanto, agora o esforço para criticar a inércia da sociedade branca frente às questões raciais cedeu lugar a uma dramaturgia que explicita as crises do autor ao trabalhar com o espinhoso tema do racismo. Nesse período é introduzida também a temática da morte, simbolizando o desejo de destruição do velho para proporcionar espaço ao novo.

Ansiando abandonar certezas absolutas e se abrir ao diálogo e à escuta com quem está cotidianamente sob a ameaça do racismo, o autor confessa a necessidade da autotransformação, em um dos trechos mais poéticos da peça:

Quando se retira o cadáver e a sala de velório fica vazia, com o resto do cheiro do formol e dos lírios no ar, é ali que o outro entra, é dali que ele fala, é ali que há espaço para ele. Ali, onde algum dia, alguém dentro de nós morreu. Um alguém, que também era uma parte nossa. (Ibid., p. 43-44) 
Diferentemente da camada real dos depoimentos, a família - composta por pai, filho e tia - se encontra no universo ficcional do texto e se mantém durante toda a peça na sala da casa, não se abalando com os acontecimentos ocorridos "fora" de seu bunker. Abstendo-se das relações com os vizinhos, suas preocupações se restringem a frivolidades, como venda de um terreno, compra de um carro, namorada do sobrinho, doenças, sexo, falta de dinheiro, vontade de viajar etc.

Identificamos nessas cenas, ainda que muito sutil, uma crítica à classe média encerrada em condomínios superseguros, mas alheia às adversidades do mundo externo ao seu habitat. $O$ discurso sobre privilégios se torna inverossímil e deslocado perante as demais situações nas quais a família está inserida.

Os diretores Alexandre Dal Farra e Janaina Leite usaram e abusaram da sobreposição de recursos pós-dramáticos na encenação: palco nu, reprodução de vídeos pré-gravados, voz em off, projeção ao vivo, iluminação branca, delimitação dos espaços feitos por objetos cênicos, corpos desfigurados, gestos e movimentos contidos e exagerados, microfones, presença do diretor em cena, negação da identificação ator-personagem, mascaramento e outras mais.

A desconstrução do espaço cênico acompanha com precisa veracidade a história contada sobre o palco. No começo da encenação tudo está em seu devido lugar, aparentando tranquilidade e segurança. Nas últimas cenas, o espaço do narrador é quebrado a pauladas por um dos intérpretes, deixando cadeiras e objetos estirados no assoalho. A superfície da sala familiar, inicialmente limpa, ao final da peça aparece coberta por litros de líquido branco.

O cenário, despojado de artefatos ilusórios, delimita com precisão as três dimensões espaciais solicitadas pelo texto: o quarto do menino, determinado pela grama verde no piso à esquerda; ao centro peles de animais mortas circunscrevem a sala; e à direita uma mesa e um telão para as cenas dos relatos e das projeções. Expediente cênico interessante resulta da projeção do rosto do narrador ao fundo do palco quando, simultaneamente, o público pode visualizá-lo lendo o texto ao microfone no primeiro plano. A sobreposição das imagens concede neutralidade aos relatos que narram a escrita dos três textos. 
As cenas narradas utilizam um recurso épico bastante explorado na atualidade, a não identificação ator-personagem pelo público. Todos os atores envolvidos na peça assumem no decorrer do espetáculo a função de narradores, inclusive o dramaturgo e diretor do espetáculo, que se faz presente no palco para ler a resposta à provocação de um dos artistas negros convidados. A troca regular de narradores acentua o caráter documental produzindo o estranhamento necessário para diferenciar a ficção da realidade.

As interpretações artificiais acrescentam sentido ao trabalho dos intérpretes. Os corpos coisificados, desprovidos de psicologismo e história, apresentam-se imunes de sentimentos ou sensações. Janaina Leite (tia) sacode-se ininterruptamente como se indicasse o desconforto do personagem perante as situações; Clayton Mariano (pai) compõe fisicamente um personagem mórbido, sem energia, que não consegue conectar-se nem mesmo ao filho; e André Capuano (filho) apresenta-se corporalmente disforme, como se não tivesse forças para aguentar o próprio peso.

Os corpos e gestos dos atores, assim como as entonações, soam propositalmente artificiais, compartilhando com o público uma ferrenha crítica ao comportamento dissimulado dos personagens brancos quanto aos problemas alheios. Durante a peça, uma massa pastosa ora é expelida pela boca, ora é retirada do sexo do pai, ora é pintada nos rostos dos personagens, como que desejando informar à audiência: achávamos que éramos diferentes, mas não, somos culturalmente brancos e estamos agora nos assumindo como seres racistas!

A sobreposição de estímulos visuais somada à profusão de assuntos do roteiro dramatúrgico resultou em um espetáculo truncado e de difícil comunicação com a plateia. Somente a análise cartesiana não auxilia no entendimento do espetáculo. As diversas reescritas do texto - que teve, inclusive, partes suprimidas e acrescentadas durante as temporadas - geraram material para vários espetáculos sobre ou correspondentes ao tema.

Entretanto, em entrevista dada a Matteo Bonfito (2013), Erika Fischer-Lichte, pesquisadora e professora de teatro contemporâneo, afirma que as produções teatrais não devem se objetivar apenas nas operações mentais. Sobre leitura de espetáculo, comentou: 
Receber; eu não diria ler, porque ler é apenas intelectual, e o interessante sobre as performances é que envolve tudo: intuições, emoções, respostas, energia; envolve tudo isso mais a cognição. Eu não separaria uma coisa da outra. Tudo está envolvido e já que cada um de nós traz consigo alguma coisa para dentro da performance, as respostas serão diferentes. (Ibid., p. 134)

Agregamos à reflexão acima o pensamento da artista Fayga Ostrower (1998): "a percepção mobiliza todo nosso ser sensível, associativo, inteligente, imaginativo e criativo. Perceber é sinônimo de compreender" (p. 73). Perceber, nesse sentido, relaciona-se à função de atribuir significados a estímulos sensoriais, propondo interpretarmos e organizarmos as informações por meio dos sentidos e não apenas pelo intelecto.

Lançando mão de recursos fenomenológicos para examinar o espetáculo, observamos que a ausência física ou alusiva do negro em uma montagem destinada a discutir o racismo no mínimo incomoda. Esclarecemos que não estamos valorando ou reclamando a presença de negros na obra, apenas registrando um ponto da montagem que nos chamou bastante atenção. A abstenção na encenação do ser que sofre a ação do arraigamento cultural do racismo reflete a ausência do negro na vida social do país em espaços públicos, como universidades, teatros, cinemas, salas de consertos, aeroportos, restaurantes, academias, escritórios comerciais e médicos, congressos e palestras, programas de televisão, ou seja, as pessoas de fenótipo de pele escura estão desprivilegiadas das possibilidades cedidas à classe média.

A ausência também revela que para a comunidade branca não há jogo de poder, pois ela só enxerga a si mesma, não tendo abertura para considerar que oprime o vitimado! A sociedade hegemônica discute as questões pertinentes à branquitude ausentando-se das reivindicações e dos direitos dos não brancos, desconsiderando que o conflito se nutre desta interdependência! Ausentar uma parte do problema inviabiliza o florescimento de um acerto ético equilibrado! Portanto, nas entrelinhas, a ausência denota o abismo existente no desequilíbrio da balança social que pende somente para o lado do afrodescendente.

Aqui nos parece estar um nó indesatável do projeto e os motivos geradores de acusações e defesas ao espetáculo. Para os negros contemporâneos, 
sabedores e conhecedores de seus direitos sociais, os caminhos de luta contra o racismo estão claros e desenhados; nesse sentido, a ausência da raça na peça reforça e legitima a sua exclusão do universo branco. Por outro lado, para o branco distanciado das questões étnicas a ausência do negro na cena poderia levá-lo a perceber a necessidade do outro para se completar a comunicação.

A ausência se configura e permanecerá como ferramenta de desigualdade, na medida que o negro for impossibilitado de usufruir dos privilégios ofertados pela sociedade aos civis em geral e o branco se posicionar abstêmio da responsabilidade no combate à desigualdade social.

No esforço de desenhar o lugar de fala do branco, Dal Farra explicitou sua própria dificuldade em desterritorializar o olhar para se lançar à aventura da escuta e aceitação dos que pleiteiam legítimos direitos sociais. Dessa maneira, efetivamente, tanto o texto como o espetáculo Branco: o cheiro do lírio e do formol configuram-se como um excelente material de estudo para futuras reflexões e investidas teatrais a respeito do tema racismo.

Conscientes ou não do arrojo da proposta, corajosamente a equipe abraçou o perigo e se dispôs a realizar o intento. Mesmo agindo em um campo de incertezas para exprimir o racismo pelo olhar da branquitude, os integrantes do projeto se lançaram no processo como quem se lança ao mar desprovido do conhecimento de nadar, imbuídos da dignidade da função do artista que se compromete a correr riscos, discutir tabus da sociedade, investigar fissuras e, acima de tudo, se deparar com seus próprios demônios e expiar sua culpa, para que novos horizontes se abram.

Para finalizar, cabe ressaltar que para se chegar ao discurso artístico potente, há a necessidade de exaustivas experimentações, aceitações dos descaminhos e infinitas reorganizações. O mérito de Dal Farra, nesse trabaIho, não se encontra em ter achado a estrada que o conduzirá à denúncia do silêncio da classe dominante frente às atrocidades sociais, mas em ter corajosamente iniciado a tortuosa caminhada. O primeiro passo foi dado para que resultados satisfatórios sejam apreciados futuramente. 


\section{Referências bibliográficas}

BONFITO, M. Entrevista com Erika Fischer-Lichte. Conceição/Conception, Campinas, v. 2, n. 1, p. 131-141, 2013. Disponível em: <https://goo.gl/mxcqnr>. Acesso em: 16 nov. 2017.

CARDOSO, L. Retrato do branco racista e anti-racista. 2010. Disponível em: <https://goo.gl/tX7PhG>. Acesso em: 15 dez. 2017.

DAL FARRA, A. Branco: o cheiro do lírio e do formol. São Paulo, 2017.

OSTROWER, F. A sensibilidade do intelecto. Rio de Janeiro: Campus, 1998.

Recebido em 17/10/2017

Aprovado em 23/10/2017

Publicado em 26/12/2017 